\title{
Growth Hormone-Producing Pituitary Gland Carcinoma
}

National Cancer Institute

\section{Source}

National Cancer Institute. Growth Hormone-Producing Pituitary Gland Carcinoma. NCI Thesaurus. Code C5963.

A rare, hormonally functioning or non-functioning pituitary gland adenocarcinoma that produces growth hormone. It may be associated with acromegaly. 